\title{
Fuel additives put under scrutiny - again
}

[WASHINGTON] The US Environmental Protection Agency (EPA) has asked an expert panel to review possible health and environmental problems associated with the 'oxygenates' that are added to vehicle fuel to help curb air pollution.

The review is the fourth major study of the issue commissioned by the EPA since 1996. It follows a report last November by researchers at the University of California questioning the benefit of fuel oxygenates and calling for the phasing out of the most common additive, a petroleum product known as methyl tertiary-butyl ether (MTBE).

The use of oxygenates such as MTBE and ethanol has been controversial since 1990, when Congress ruled that gasoline should be reformulated to contain at least two per cent oxygen. This was meant to reduce toxic air pollutants and exhaust emissions that contribute to smog. In addition, fuels sold in some areas were required to contain at least 2.7 per cent oxygen during the winter to fight carbon monoxide pollution.

Shortly after MTBE entered wide use in 1992, however, health officials began receiving complaints of headaches, nausea and other adverse effects. That prompted a spate ofEPA-requested studies.

A 1996 review of the literature by the Boston-based Health Effects Institute (HEI), which is funded by the EPA and industry, was followed by a National Academy of Sciences study. These fed into an assessment by the White House science office published last year. All three found insufficient evidence to warrant a ban on MTBE, or even a reduction in its use, and called for more research.

In 1997 the State of California, which has its own reformulated gasoline programme, asked researchers at the University of California to conduct another review of the literature on oxygenates. Their report recommends that the state should consider phasing out MTBE over several years and let refiners switch to other types of cleaner-burning gasoline, without the oxygenates.

The conclusion had less to do with new evidence on harmful effects of MTBE research on the topic remains sparse - than with a judgement that oxygenates contribute little to cleaning up air pollution. Their primary claimed benefit, reducing carbon monoxide emissions, is difficult to prove.

Cleaner-burning cars may be at least as responsible for the decline. In fact, said the University of California researchers, "MTBE and other oxygenates were found to have no significant effect on exhaust emissions from advanced technology vehicles".

They did no better at reducing the toxic air pollutant benzene than did other kinds of reformulated gasoline. But they increased emissions of formaldehyde, known to cause cancer in animals.

In addition, according to the 1996 academy study and others (but not according to the EPA or last year's White House study), oxygenate levels of 2.7 per cent in winter fuels may even add to pollution by producing nitrogen oxides, one of the main offenders in creating urban smog.

The new review will be chaired by HEI president Daniel Greenbaum, who says it will be the first time all interested parties researchers on air and water quality, health

\section{Russian physicists may pay price of success}

[Moscow] Two researchers in the Russian Academy of Sciences have warned that a new tax code being discussed in the Russian parliament "could kill Russian science rather than support it".

The warning has come from Eduard Kruglyakov and Veniamin Sidorov, who work at the Novosibirsk Nuclear Physics Institute (NNPI) of the academy's Siberian branch. The institute is a rare example of a successful and self-financing Russian scientific organization, having lost only 15 per cent of its staff during the hard times of perestroika.

Unlike many research institutes, NNPI can still afford equipment and pays salaries regularly, allowing it to continue research in fundamental areas of high-energy physics, the physics of accelerators, plasma and controlled thermonuclear synthesis.

The institute stays in operation primarily through the production and sale

of high-technology equipment, such as particle accelerators, low-dose X-ray machines, and instruments for studying high temperature plasma.

The money collected in this way has made up for the lack of government support. But the new tax code will treat these revenues as profit, and subject to taxation.

"It is hardly possible to equate profit which is spent on buying villas at prestigious resorts, increasing personal bank accounts, or even paying dividends to shareholders, with that which is entirely used for supporting fundamental research," say Kruglyakov and Sidorov.

Writing in the local newspaper of Novosibirsk academic town, which depends entirely on research institutes, they argue that "when the state is unable to finance its science, it has no moral right to tax a scientific organization's profit as if it was just a commercial enterprise". Carl Levitin

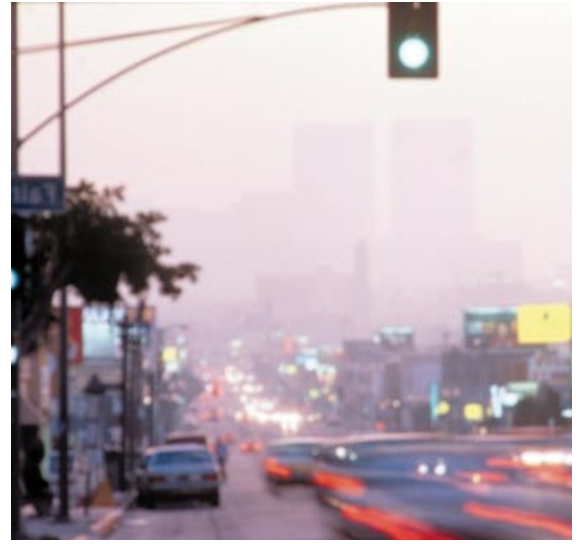

Smog warning: oxygenates added to winter fuels may increase pollution rather than curb it.

officials, environmentalists and oil industry representatives - will meet to discuss the oxygenates issue. Their report is due in June.

Greenbaum says there have been some new developments since HEI's last report on the subject in 1996, although "we haven't had a lot of brand new scientific information". Additional concerns have been raised about the ingestion of MTBE via drinking water.

The substance percolates easily through groundwater, and some communities have experienced acute episodes of water pollution after underground storage tanks ruptured. The pro-MTBE Oxygenated Fuels Association argues that the leaky tanks, not the oxygenates, are the problem.

Among the many open research questions on MTBE are how it is metabolized, and what the levels of exposure in the general population are. Based on their review, the University of California researchers concluded that MTBE is an animal carcinogen with the potential to cause cancer in humans.

But, according to Greenbaum, three other groups - the International Agency for Research on Cancer, the National Institute of Environmental Health Sciences in North Carolina, and the California Office of Environmental Health Hazard and Assessment - have recently concluded that MTBE is not a likely human carcinogen.

Scientific questions may not ultimately decide the oxygenates issue. Politicians from states with strong farming communities have lobbied for the use of ethanol, a cornbased oxygenate, while representatives from California and Maine have pushed to exempt their states from the federal requirements.

If the additives are phased out, the University of California researchers recommended caution in approving any alternatives. "Addition of any chemical compound to the environment in quantities that constitute a significant fraction of the total content of gasoline may have unexpected environmental consequences."

Tony Reichhardt 